\title{
Ornacitrus: Development of Genetically Modified Anthocyanin-expressing Citrus with Both Ornamental and Fresh Fruit Potential
}

\author{
Manjul Dutt' ${ }^{1}$, Daniel Stanton, and Jude W. Grosser \\ Horticultural Sciences Department, Citrus Research and Education Center, University of Florida, \\ 700 Experiment Station Road, Lake Alfred, FL 33850
}

\begin{abstract}
AdDitional Index words. genetic engineering, 'Mexican' lime, MYB gene, purple citrus
Abstract. Anthocyanins are beneficial bioflavonoids that have numerous roles in human health maintenance, disease prevention, and overall well-being. In addition, anthocyanins are key to the consumer appeal of many ornamental plants. Most citrus (Citrus L.) plants do not produce anthocyanins under warm tropical and subtropical conditions. Anthocyanin pigments, responsible for the "blood" color of blood orange [Citrus sinensis (L.) Osbeck], are produced after exposure to cold conditions during the fruit's development. The transcription factor Ruby is responsible for the production of anthocyanin in blood orange. Functionally, similar genes exist in other fruit crops such as grape [Vitis vinifera L. (VvmybA1 and VvmybA2)] and apple [Malus $\times$ domestica Borkh (MdMYB10)]. Here, VvmybA1 and Ruby genes were constitutively expressed in 'Mexican' lime (Citrus aurantifolia Swingle). This cultivar performs optimally under Florida's humid subtropical environment and has a short juvenile phase. Constitutive expression of $V v m y b A 1$ or $R$ uby resulted in anthocyanin pigmentation in the leaves, stems, flowers, and fruit. An increased pigmentation of the outer layer(s) of stem tissue was observed in 'Mexican' lime overexpressing the $V v m y b A 1$, whereas lower anthocyanin levels were observed in plants overexpressing Ruby. Enhanced pigmentation was also observed in the young leaves; however, pigment intensity levels decreased as the leaves matured. Flower color ranged from light pink to fuchsia and the fruit pulp of several 'Mexican' lime lines were maroon; similar to a blood orange. The results demonstrate that expression of anthocyanin-related genes can affect temporal pigmentation patterns in citrus. It also opens up the possibility for the development of modified blood orange and other cultivars adapted to the subtropical environment.
\end{abstract}

Anthocyanins are plant pigments responsible for the coloration in many fruits, vegetables, and flowers, whereas others are colorized by carotenoids and betalains. These red/violet pigments impart an aesthetic appeal to the cultivars in which they are expressed. Anthocyanin pigments are present in many plant tissues. However, they are more visible in flowers and fruit. They have been consumed by humans and animals since prehistoric times without any side effects (Brouillard, 1982). Anthocyanins belong to the flavonoid group of phytochemicals that provide several therapeutic properties potentially beneficial to human health if consumed in adequate quantities (Bridle and Timberlake, 1997; Saija, 1994). Anthocyanins contribute to free radical scavenging (De Beer et al., 2003; Sánchez-Moreno, 2002) and have potent in vitro antioxidant capacities (Deighton et al., 2000; Lila, 2004; Wang et al., 1997). Numerous pharmacological studies have implicated their intake on the prevention of a number of human health issues such as obesity and diabetes (Tsuda et al., 1996, 2003). In addition to their health benefits, anthocyanins are bacteriostatic (Naz et al., 2007) and have been widely used as a natural source of food colorants (Manach et al., 2004).

Anthocyanins are synthesized by the flavonoid biosynthesis pathway (Holton and Cornish, 1995). These water-soluble pigments are produced through a complex expression of several genes such as MYB transcription factors, basic helix-loop-helix (bHLH) transcription factors, and WD-repeat proteins (Baudry et al., 2004; Irani et al., 2003). Several MYB regulators of anthocyanin production have been cloned in recent years.

Received for publication 25 Aug. 2015. Accepted for publication 4 Nov. 2015. ${ }^{1}$ Corresponding author. E-mail: manjul@ufl.edu.
When overexpressed in heterologous systems, these transcription factors resulted in an enhanced overexpression and accumulation of anthocyanins (Borevitz et al., 2000; Gonzali et al., 2009; Meng et al., 2014). It has been observed that there is a requirement for the presence of a suitable bHLH partner to achieve full functionality in the heterologous system (Espley et al., 2007; Li et al., 2007; Takos et al., 2006).

The blood orange is rich in anthocyanins (Hillebrand et al., 2004) and arose as a mutation of the common blond orange during the 16th century. Blood orange contains a copia-like retrotransposon inserted in the promoter region of a MYB transcription factor named Ruby. This gene is responsible for transcriptional activation of anthocyanin production in blood orange (Butelli et al., 2012). Blood orange is mainly cultivated in Sicily and southern Italy (Bridle and Timberlake, 1997). When grown in the subtropical sweet orange belt, these oranges do not accumulate adequate anthocyanins and, thus, cannot develop the characteristic deep red coloration that is observed in fruit produced in cooler climates (Lee, 2002).

Development of genetically modified citrus with the ability to overexpress anthocyanins can have two potential benefits. The first benefit is that it would allow the cultivation of these healthy fruit in the major subtropical citrus belt and/or the production of ornamental citrus plants, depending on the cultivar. The second benefit is that novel fruit, leaf, and flower colors could be produced by regulating anthocyanin biosynthesis (Xiaonan and Qixiang, 2002). Here, we demonstrate the stable expression of two MYB transcription factors and subsequent anthocyanin production in 'Mexican' lime (VvmybAl cloned from the red grape 'Ruby Seedless' and Ruby cloned from the 'Moro' blood orange) and results are presented on their expression. 


\section{Materials and Methods}

Vector CONSTRUCTION. Fruits of the red grape 'Ruby Seedless' were purchased from a local supermarket, whereas fruits from the blood orange 'Moro' were obtained from R. Krueger (USDA-ARS, Riverside, CA). RNA was isolated from both 'Ruby Seedless' skin and 'Moro' blood orange pulp using an RNeasy plant mini kit (Qiagen, Valencia, CA). Reverse transcription polymerase chain reaction (RT-PCR) amplicons were generated using a OneStep RT-PCR kit (Qiagen), $500 \mathrm{ng}$ of the extracted total RNA, and gene-specific primers designed from VvmybA1 (AB097923) and Ruby (JN402334) sequences [obtained from the National Center for Biotechnology Information database (Table 1)]. These primers were designed to introduce a BamHI site immediately upstream of the translation start site and a NotI site immediately following the stop codon. Amplicons were visualized under ultraviolet light on a 1\% agarose gel containing GelRed ${ }^{\mathrm{TM}}$ (Biotium, Hayward, CA). Amplicons were isolated, purified, and cloned into pGEM $^{\circledR}-\mathrm{T}$ plasmid (Promega, Madison, WI). The sequences were verified by Sanger sequencing. Fragments were ligated into a unique BamHI/Not I cloning site that lay between a double enhanced CaMV 35S promoter (D35S) and a CaMV 35S terminator (35S-3'). The promoter-gene cassette was inserted into a plant transformation vector containing the $n p t I I$ selectable marker gene. The resulting binary plasmid was introduced into the Agrobacterium tumefaciens (Smith and Towns) Conn strain EHA105 (Hood et al., 1993).

Plant materials. Epicotyl segments, originating from juvenile nucellar seedlings of 'Mexican' lime, were excised and cut obliquely into $2.5-\mathrm{cm}$-long segments to expose the cambial ring. The $A$. tumefaciens cells were grown overnight and epicotyl segments were transformed as described by Dutt and Grosser (2009). Plants were selected based on the level of anthocyanin production in the regenerating shoots (either on the leaves or the stem). Elongated transgenic shoots were micrografted in vitro onto Carrizo citrange [Citrus sinensis $\times$ Poncirus trifoliata (L.) Raf.] as outlined by Dutt and Grosser (2010) to expedite the recovery of transgenic plants. The grafted shoots were potted into a peat-based commercial potting medium and acclimated to greenhouse conditions.

HoRTICULTURAL MANIPULATIONS TO INDUCE RAPID FLOWERING. An ex vitro micrografting technique (Dutt and Grosser, 2010) was used to clonally propagate the transgenic anthocyanin overexpressing shoots. Tender shoots obtained from greenhouse acclimated mother plants were micrografted onto actively growing 6-month-old Carrizo citrange rootstocks and maintained in a greenhouse that was shady $(60 \%$ to $80 \%)$ and humid $(80 \%$ to $90 \%$ ). Plants with active growth shoots were potted in 18.9 -L pots and maintained in a greenhouse with $40 \%$ shade. Trees were sprayed with micronutrients and fertilized with a $20 \mathrm{~N}-4.4 \mathrm{P}-$ 16.6K fertilizer (Peat Lite; JR Peters, Allentown, PA) as per manufacturer's recommendations. Trees were allowed to grow under the above conditions for 2 years before girdling. Girdling was performed on the rootstock $\approx 15 \mathrm{~cm}$ above the potting medium surface in the fall. A sharp cut $(\approx 1 \mathrm{~mm}$ wide) was made to completely encircle the stem, and the bark was not removed during girdling. The cut was made deep enough to disrupt the phloem tissues only.

Molecular anAlysis OF TRANSFORMANTS. DNA was isolated from $100 \mathrm{mg}$ of leaf tissue using a GenElute ${ }^{\mathrm{TM}}$ Plant Genomic DNA Miniprep Kit (Sigma-Aldrich, St. Louis, MO). PCR was carried out to confirm presence of the transcription factor transgene using a GoTaq ${ }^{\circledR}$ Green Master PCR Mix (Promega), $25 \mathrm{~nm}$ of the isolated DNA, and the gene-specific primers described above. PCRs were run on a thermal cycler (C1000 Touch; Bio-Rad Laboratories, Hercules, CA). To quantify the production of $V v m y b A 1$ or Ruby in the different plant parts, RNA was isolated from $100 \mathrm{mg}$ of leaf tissue as described earlier and reverse transcription real-time PCR (RT-qPCR) primers and probes were designed to detect $V v m y b A 1$ or Ruby amplicons using PrimerQuest ${ }^{\mathrm{SM}}$ online software (Integrated DNA Technologies, Coralville, IA). The probes were labeled with a 6-carboxy-fluorescein reporter dye at the $5^{\prime}$-end and with Black Hole Quencher (BHQ)-1 at the 3' -end. The housekeeping gene $18 S$ rRNA was used as an endogenous control (Table 2). RT-qPCR reactions were performed with a final $20-\mu \mathrm{L}$ reaction volume using a TaqMan ${ }^{\circledR}$ RNA-to-Ct ${ }^{T M}$ OneStep kit (Applied

Table 1. Forward and reverse primer sequences used in cloning of the two MYB genes. RNA was used as a template and a one-step reverse transcription polymerase chain reaction was used to amplify the selected cDNA.

\begin{tabular}{llc}
\hline Gene & Forward primer & Reverse primer \\
\hline$V v m y b A 1$ & GGATCCATGGAGAGCTTA GGAGTTA & GCGGCCGCTCAGATCAAGTGATTTACT \\
Ruby & GGATCCATGGCGGATTCCTTAGGAGT & GCGGCCGCTTACTTTGCATTGAGAAGA \\
\hline
\end{tabular}

Table 2. Primers and probe used in the one-step real-time, reverse transcription polymerase chain reaction assay for the detection of the transcription factor transcripts.

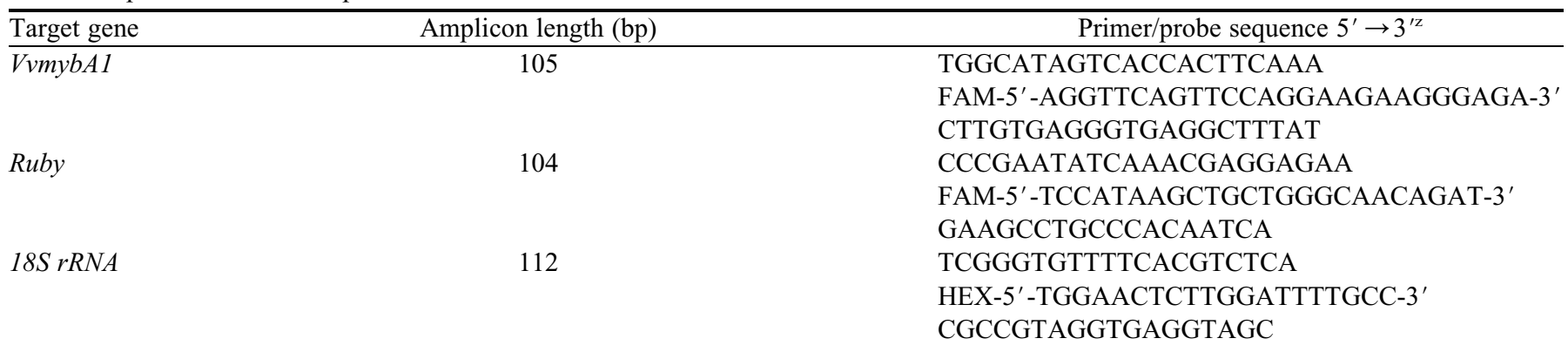

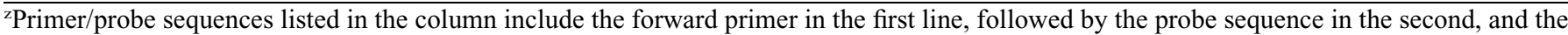
reverse primer sequence in the third line. 

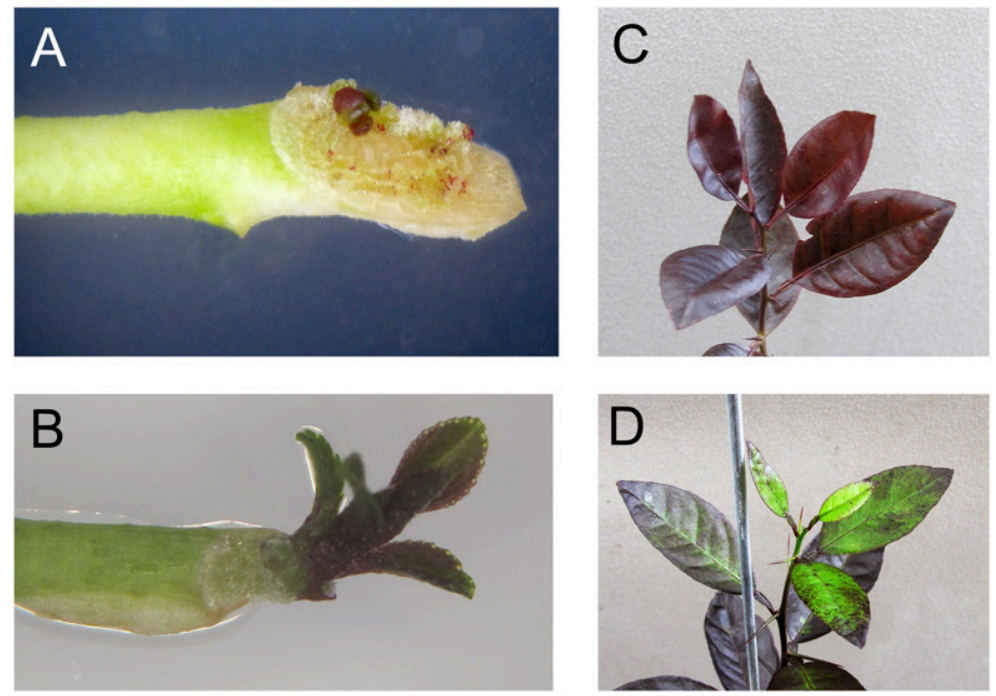

Fig. 1. (A) An anthocyanin-expressing bud emerging in a selection medium after Agrobacterium tumefaciensmediated transformation of 'Mexican' lime explants. (B) An anthocyanin overexpressing shoot is ready for micrografting to Carrizo citrange rootstock. (C) An anthocyanin overexpressing transgenic line is exhibiting intense pigmentation, curled leaves, and a lack of vigor. (D and E) Normal anthocyanin overexpressing in a transgenic line vigorously growing in the greenhouse.
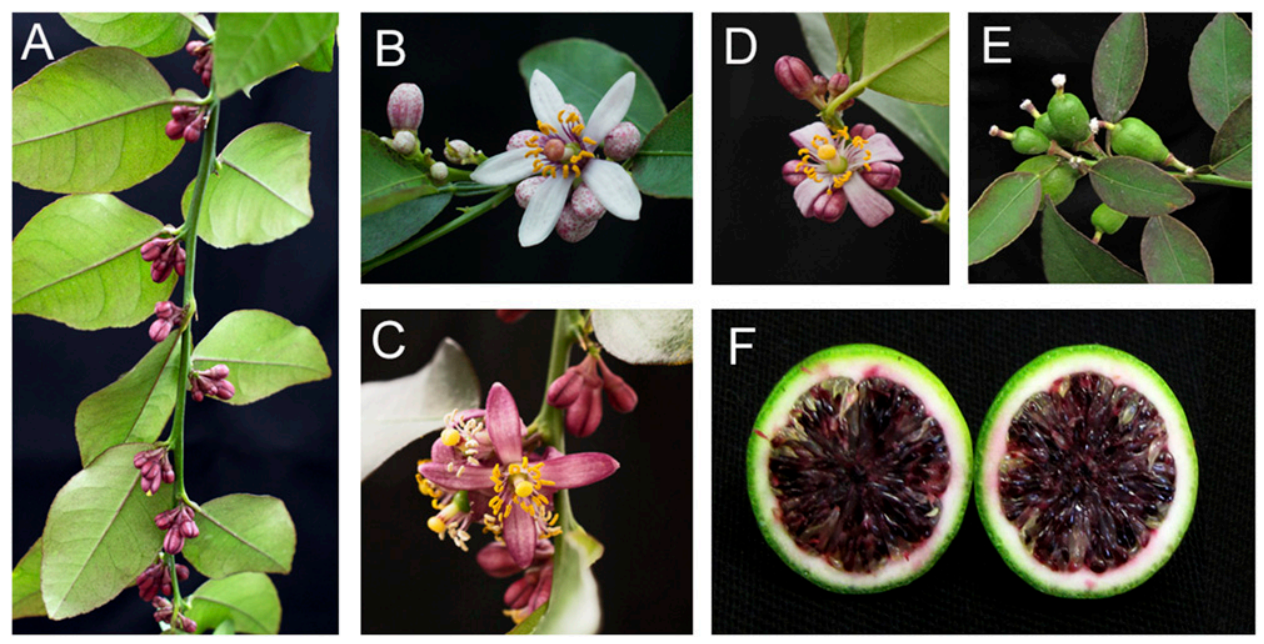

Fig. 2. (A) Flower clusters on a $V v m y b A l$ overexpressing 'Mexican' lime transgenic line. (B and C) Close-up of flowers on two independent $V v m y b A l$ overexpressing lines. (D) Close-up of flowers on a Ruby overexpressing line. (E) A fruit cluster on a $V v m y b A 1$ overexpressing 'Mexican' lime line. (F) A cross-section of a fruit from a $V v m y b A 1$ overexpressing 'Mexican' lime line demonstrating the production of anthocyanin in the pulp.
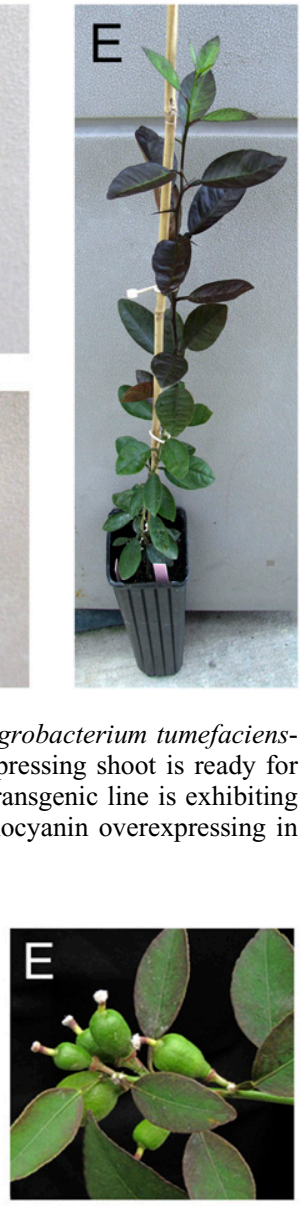

Biosystems, Foster City, CA) and reactions were run on a thermocycler (ABI PRISM 7700, Applied Biosystems) according to manufacturer's instructions. The one-step kit parameters consisted of 20 min incubation at $48^{\circ} \mathrm{C}$ followed by $10 \mathrm{~min}$ incubation at $95^{\circ} \mathrm{C}$ and 40 cycles at $95^{\circ} \mathrm{C}$ for $15 \mathrm{~s}$ and $60{ }^{\circ} \mathrm{C}$ for $1 \mathrm{~min}$. RNA from a nontransgenic greenhouse 'Mexican' lime plant was used as a negative control, and the data were normalized using the housekeeping gene as described above. Experiments were conducted in triplicate and were repeated at least twice. Relative quantitation was measured and analyzed by the comparative $\mathrm{Cq}$ method $\left(2^{-\Delta \Delta \mathrm{Ct}}\right)$. The fold change in the relative expression was then determined by calculating $2^{-\Delta \Delta \mathrm{Ct}}$ as described by Livak and Schmittgen (2001).

Light Microscopy. Stems were cut into pieces $(1-\mathrm{cm}$ pieces for longitudinal sections and $2.5-\mathrm{mm}$ pieces for cross-sections) and processed for microscopy. Stem pieces were arranged and mounted in Tissue Tek Cryo-OCT Compound (Thermo-Fisher Scientific, Waltham, MA) on a brass stub. The stubs were frozen and $40-\mu \mathrm{m}$ sections of tissue were cut using a WRC cryostat microtome (Harris Manufacturing, North Billerica, MA). The sections were mounted in Optic Mount I (Mercedes Medical, Sarasota, FL) on glass slides and a cover slip was placed over the top of the sections. The sections were observed using a fluorescence microscope (BX61; Olympus America, Melville, NY). Light micrographs were captured using a digital camera (14MP; OMAX, Irvine, CA). Final plates were constructed in Photoshop CC (Adobe Systems, San Jose, CA).

\section{Results and Discussion}

Production of transgenic Plants. A population of transgenic lines expressing either the VvmybAl or the Ruby transcription factor under the control of the $\mathrm{d} 35 \mathrm{~S}$ promoter was obtained. These transcriptional activator (MYB) genes cloned from blood orange and grapevine appear to enhance the expression of all genes in the anthocyanin biosynthesis pathway (Azuma et al., 2007; Butelli et al., 2012; Jeong et al., 2006). 'Mexican' lime is considered to be recalcitrant to $A$. tumefaciens-mediated transformation (Dutt et al., 2009); however, it was relatively easy to select the few transgenic shoots from the majority of nontransformed ones based on color in
Fig. 3. Cross-sections of a transgenic Ruby overexpressing 'Mexican' lime fruit with a control nontransgenic fruit for comparison.

J. AMER. SOC. HorT. SCI. 141(1):54-61. 2016. 

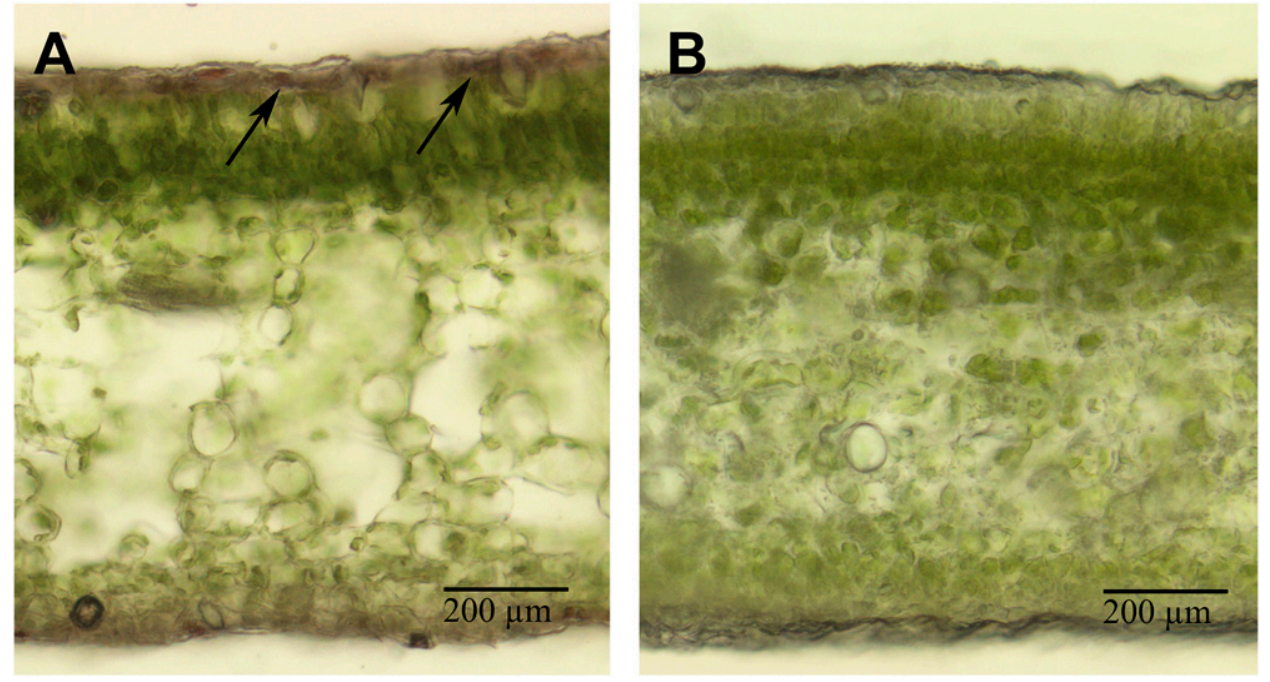

Fig. 4. Cross-sections of a transgenic VvmybAl overexpressing 'Mexican' lime leaf (A) and a nontransformed control (B). The arrows indicate anthocyanin overexpression in leaf epidermal cells.
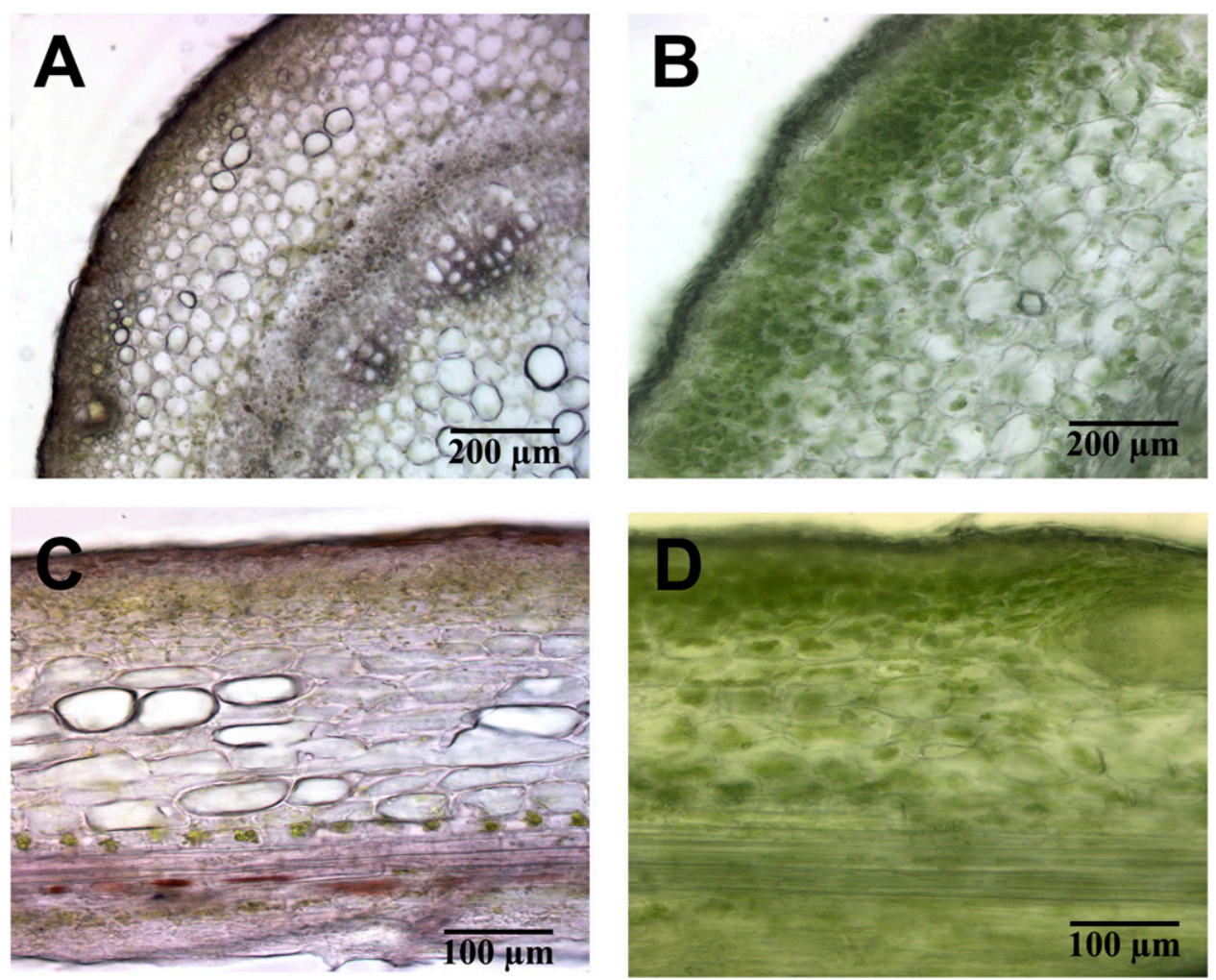

Fig. 5. (A) Cross-section of a transgenic VvmybA1 overexpressing 'Mexican' lime stems demonstrating anthocyanin expression localized to the epidermis, phloem, and xylem of transgenic plants compared to the control (B). Longitudinal sections of stem confirm that only transgenic stems (C) exhibit anthocyanin expression in the epidermis, phloem, and xylem (not shown). Anthocyanins were absent in longitudinal sections of the nontransformed control (D).

either leaves or stem or both (Fig. 1A and B). It is possible that some lines that could potentially express the transgene(s) in other plant organs or later on developmentally were not selected by this process.

Visual Characterization of the transgenic plants. Transgenic plants were observed to be phenotypically normal and grew well after being micrografted onto standard Carrizo rootstocks. Plants could be greenhouse acclimated in 6-8 weeks post-transformation. Fourteen transgenic lines expressing the $V v m y b A 1$ transcription factor and six lines expressing the Ruby transcription factor were successfully acclimated. $V v m y b A 1$ overexpression potentially had a detrimental effect on two of our regenerated transgenic lines. These plants exhibited intense pigmentation, curled leaves, and a lack of vigor (Fig. 1C). These lines remained stunted and did not grow beyond $15 \mathrm{~cm}$, even after 2 years in the greenhouse. Accordingly, they were excluded from this study. Similar results have been observed in previous studies following overexpression of Lc (Goldsbrough et al., 1996) and VvmybAl (Stover et al., 2013) transcription factors. Anthocyanin production is metabolically expensive. It is probable that there is an anthocyanin production threshold where the overexpression of the MYB genes results in toxic levels of anthocyanin that inhibit plant growth and development (Bradley et al., 1998). It is also possible that certain T-DNA insertions could have resulted in the disruption of specific gene(s) in the citrus genome that are needed for normal growth and development (Vlachonasios et al., 2003; Zheng et al., 2005).

Results presented here are for four randomly selected, phenotypically normal, transgenic lines generated with each transcription factor construct. Regenerating in vitro shoots overexpressing the VvmybAl transcription factor were deep purple in color. Visually, the anthocyanin levels remained steady in the micrografted plants and the pigmentation levels decreased as the leaves matured. In contrast, shoots overexpressing the Ruby transcription factor had little or no initial in vitro coloration. Anthocyanin levels increased in the micrografted plants with expression confined to the younger leaves. Anthocyanin levels subsequently decreased as the leaves matured. Stems were also highly pigmented in $V v m y b A 1$ transcription factor overexpressing juvenile plants, and decreased on maturity. This expression pattern has also been observed in other plants overexpressing anthocyanin (Bradley et al., 1998; Qiu et al., 2014). Anthocyanins are produced by the flavonoid biosynthetic pathway via the phenylpropanoid pathway and a number of genes are 

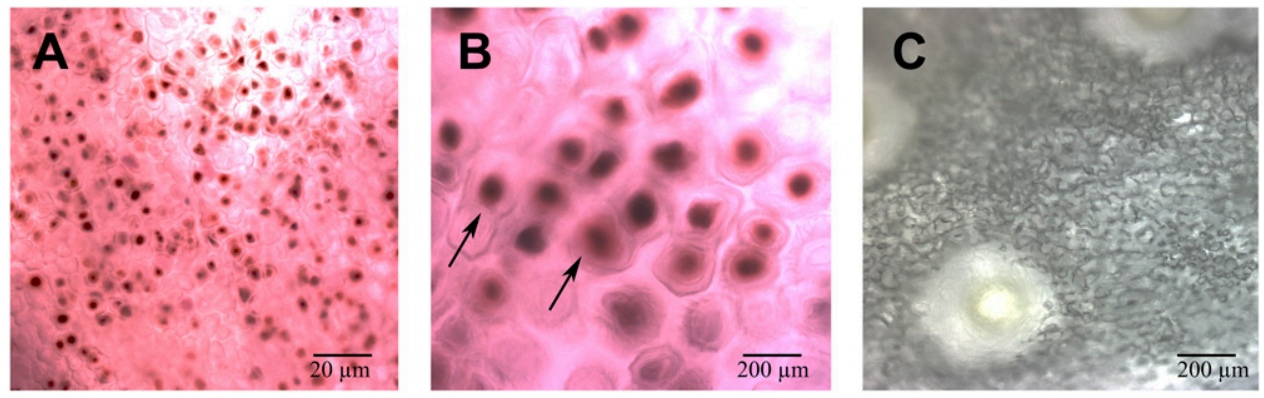

Fig. 6. The epidermis of a transgenic $V v m y b A l$ overexpressing 'Mexican' lime flower petal (A and B) and control petal $(\mathbf{C})$. Anthocyanin production was localized in the vacuole (see arrows).
Stiles et al., 2007), anthocyanin levels in both sets of plants were enhanced during winter months and diminished during the summer (results not shown). 'Mexican' lime does not naturally produce anthocyanins, and control plants remained green for the duration of this study. Transgene copy number, insertion location, and position effects can result in differential gene expression (Peach and Velten, 1991). Our transgenic lines produced anthocyanin in tissue-specific areas (Figs. 1

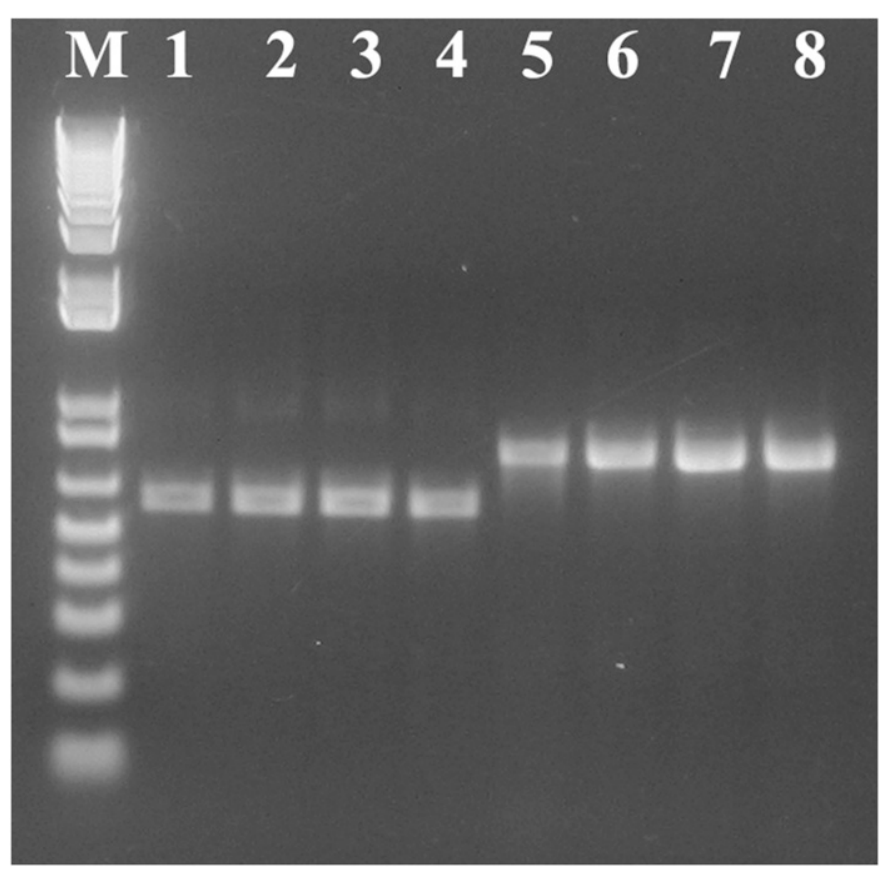

Fig. 7. Polymerase chain reaction amplicons of the $V v m y b A 1$ and Ruby genes from genomic DNA of transgenic 'Mexican' lime plants. Amplification was carried out using gene-specific primers which yielded 0.7-kb $V v m y b A 1$ fragments (lanes 1-4) and 0.8-kb Ruby fragments (lanes 5-8) that matched the expected band size determined by a 1-kb DNA ladder (lane M).

involved (Jaakola, 2013). It could be that one or more of these genes are developmentally regulated in maturing citrus. In Hedera helix L., dihydroflavonol reductase activity ceased as the plants progressed from the juvenile to the mature phase, resulting in a lack of anthocyanin accumulation in the mature phase (Murray and Hackett, 1991). Similarly, downregulation of an anthocyanidin glucosyltransferase resulted in decreased accumulation of anthocyanins during fruit ripening in strawberry [Fragaria $\times$ ananassa Duch. (Griesser et al., 2008)].

Anthocyanin levels varied among the individual lines and were observed to be temperature dependent. In grape, high temperature decreased anthocyanin accumulation in the berries. This was attributed to a combinatory effect of anthocyanin degradation and inhibition of mRNA transcription of the anthocyanin biosynthetic genes (Mori et al., 2007). MYB transcript levels can also be differentially regulated by cold stress (Agarwal et al., 2006; Camm et al., 1993) and light (Takos et al., 2006). Similar to that observed in other plant species (Lin-Wang et al., 2011; Reyes et al., 2004; and 2). Rapid flowering following the girdling of 'Mexican' lime trees has been demonstrated earlier by Dutt et al. (2011), and we observed similar results with the transgenic lines in this study. Girdling disrupts movement of photosynthates and metabolites through the phloem (Goren et al., 2004) and increases the carbohydrate levels in leaves (Li et al., 2003). Flowers from different lines had variable anthocyanin production. The fruit pulp was dark purple in the $V v m y b A 1$ and fushia in the Ruby overexpressing lines (Figs. 2F and 3). Even though our constructs had MYB genes driven by a constitutive $35 \mathrm{~S}$ promoter, anthocyanin expression was not detected in the fruit peel or in the mesocarp in any of the $V v m y b A l$ and Ruby overexpressing transgenic lines. This corroborates previous data where tissue-specific expression of transcription factors governed the distribution of anthocyanins in specific organs (Steyn et al., 2002). This also suggests that there are certain regulatory elements, likely including bHLH $R$ genes, requiring coactivation before transcriptional activation occurs. These regulatory elements could be missing in the 'Mexican' lime fruit peel, preventing anthocyanin production.

Histological analysis. Anthocyanin expression in the leaf, stems, and petals of transgenic plants was examined by histological analyses. Cross-sections of leaves showed that anthocyanin production was localized to the epidermis in transgenic plants [Fig. 4A (see arrows)], but there was no production of anthocyanins in control leaves (Fig. 4B). Likewise, crosssections of transgenic plant stems showed that the pigment was expressed in the epidermis, phloem, and xylem (Fig. 5A). These results were also confirmed in longitudinal sections (Fig. 5B). There was no pigmentation observed in control sections (Fig. 5C and D). Anthocyanin expression was localized to the vacuole in the flower petals [Fig. 6A and B (see arrows)]; however, anthocyanins expression was absent in control petals (Fig. 6C). This agrees with previous data where anthocyanins have been observed to be sequestered in the vacuole in Arabidopsis thaliana (L.) Heynh. and many other plants (Markham et al., 2000; Pourcel et al., 2010; Zhang et al., 2006). Anthocyanins are generally transported to the vacuole by the secretory pathway in cells resulting in a high accumulation of anthocyanin in the vacuole (Poustka et al., 2007).

Molecular Characterization of THE TRANSGENiC Plants. Screening of putative regenerated plants by PCR analysis confirmed the presence of the $V v m y b A l$ and the Ruby transcription factor transgene in our transgenic lines (Fig. 7). In addition, gene expression of these transcription factors was evaluated by RT-qPCR. Transcription factor expression was always higher in the younger leaves compared with mature leaves (Fig. 8). In the present study, a maximum of an 8-fold 


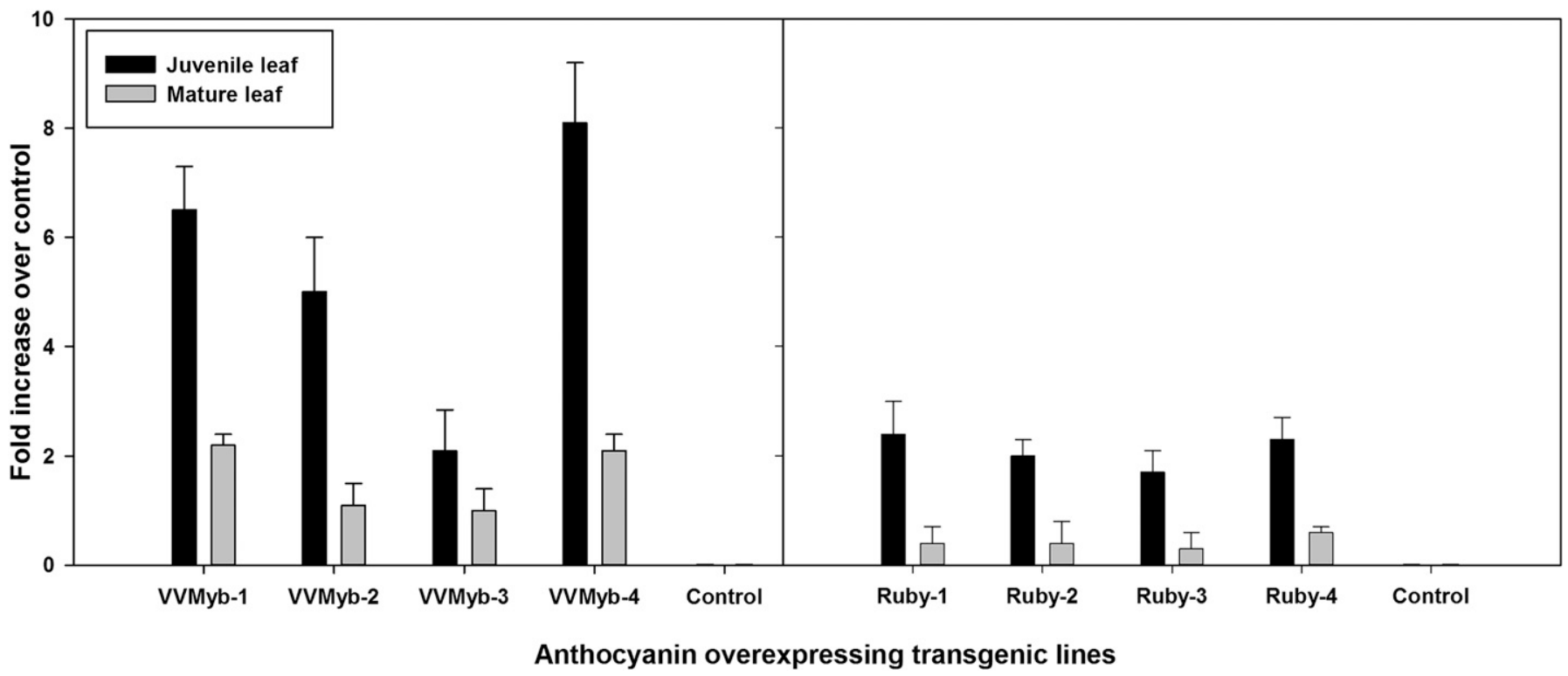

Fig. 8. Quantification of $V v m y b A 1$ and Ruby activity using reverse transcription real-time polymerase chain reaction. Four selected transgenic lines from each group were evaluated. Three independent clones were tested from each transgenic line. Total RNA from a nontransgenic control plant was also included to verify the accuracy of the amplification process. Primers used to amplify the VvmybAl and Ruby gene(s) are described in Table 2.

increase in expression of $V v m y b A l$ was observed, whereas only a 2 -fold increase in expression of Ruby was observed in transgenic 'Mexican' lime lines (Fig. 8). VVMyb-4 had the highest relative expression among the transgenic lines evaluated. This line exhibited an 8-fold increase in $V v m y b A l$ gene expression compared with the control in young leaves. Gene expression in the other $V v m y b A l$ overexpressing transgenic lines ranged from a 2 -fold to a $6 \frac{1}{2}$-fold increase in juvenile leaves compared with the control. In several plant species, juvenile reddening decreases as the leaves mature (ChalkerScott, 1999) and this plays a role in the tender leaf's defense from insect herbivory and excessive light (Karageorgou and Manetas, 2006; Steyn et al., 2002).

In certain purple-leaved ornamentals, color is maintained in the mature tissues. This phenomenon helps the plant to reduce the frequency and severity of photoinhibition (Gould et al., 2002; Neill and Gould, 2003) as well as protection from ultraviolet radiation or free radical scavenging (Burger and Edwards, 1996; Wang et al., 1997). This was not observed in our transgenic lines, where the anthocyanin levels dramatically decreased in mature leaves (Figs. 1E, 2A, and 8). We observed a 4-fold decrease in VVMyb-4 expression in mature leaves. The VVMyb-1 and VVMyb-2 lines also showed a 3-fold decrease in expression in the mature leaves, whereas expression of VVMyb-3 was reduced by half.

Anthocyanin production in Ruby overexpressing lines was much lower than that observed in the $V v m y b A l$ overexpressing transgenic lines. The Ruby lines had a 2-fold increase in the expression levels in young leaves. The transgenic line Ruby-4 had a slight reddish hue in the mature leaves, whereas leaves from the other lines were visibly indistinguishable from control leaves. In red grape berries, 29 anthocyanins have been identified of which malvidin derivatives were the most abundant anthocyanins (Liang et al., 2008). However, in blood oranges, the major anthocyanins were characterized as cyanidin 3-glucoside and cyanidin 3-(6" -malonylglucoside) (Hillebrand et al., 2004). This could indicate that the Ruby transcription factor may act in a different manner on the structural genes of the anthocyanin biosynthetic pathway in citrus when compared with the activity of the VvmybAl transcription factor. Validation of these observations with RNA sequencing studies or by analyzing the anthocyanin composition differences between the different lines is required for a conclusive interpretation.

\section{Conclusions}

Our report outlines the successful production of transgenic 'Mexican' lime plants overexpressing the VvmybAl or the Ruby MYB transcription factor, resulting in the production of anthocyanins in a citrus cultivar that does not produce anthocyanin naturally. These transgenic plants exhibited unique leaf pigmentation, flower coloration, and pulp enhanced by anthocyanin overproduction. These transgenic lines can be directly used as novel ornamentals or released for fresh fruit consumption, as anthocyanins have been shown to be beneficial to human health. In addition, our research opens up the possibility for the development of modified sweet orange or grapefruit cultivars that are anthocyanin rich and adapted to the subtropical environment. Additional information on these plants can be searched at http:// www.crec.ifas.ufl.edu/.

\section{Literature Cited}

Agarwal, M., Y. Hao, A. Kapoor, C.H. Dong, H. Fujii, X. Zheng, and J.K. Zhu. 2006. A R2R3 type MYB transcription factor is involved in the cold regulation of $\mathrm{CBF}$ genes and in acquired freezing tolerance. J. Biol. Chem. 281(49):37636-37645.

Azuma, A., S. Kobayashi, H. Yakushui, M. Yamada, N. Mitani, and A. Sato. 2007. VvmybA1 genotype determines grape skin color. Vitis 46(3):154-155.

Baudry, A., M.A. Heim, B. Dubreucq, M. Caboche, B. Weisshaar, and L. Lepiniec. 2004. TT2, TT8, and TTG1 synergistically specify the expression of BANYULS and proanthocyanidin biosynthesis in Arabidopsis thaliana. Plant J. 39(3):366-380. 
Borevitz, J.O., Y. Xia, J. Blount, R.A. Dixon, and C. Lamb. 2000. Activation tagging identifies a conserved MYB regulator of phenylpropanoid biosynthesis. Plant Cell 12(12):2383-2394.

Bradley, J.M., K.M. Davies, S.C. Deroles, S.J. Bloor, and D.H. Lewis. 1998. The maize Lc regulatory gene up-regulates the flavonoid biosynthetic pathway of Petunia. Plant J. 13(3):381-392.

Bridle, P. and C.F. Timberlake. 1997. Anthocyanins as natural food colours-selected aspects. Food Chem. 58(1-2):103-109.

Brouillard, R. 1982. Chemical structure of anthocyanins, p. 1-40. In: P. Markakis (ed.). Anthocyanins as food colors. Academic Press, New York, NY.

Burger, J. and G.E. Edwards. 1996. Photosynthetic efficiency, and photodamage by UV and visible radiation, in red versus green leaf coleus varieties. Plant Cell Physiol. 37(3):395-399.

Butelli, E., C. Licciardello, Y. Zhang, J. Liu, S. Mackay, P. Bailey, G. Reforgiato-Recupero, and C. Martin. 2012. Retrotransposons control fruit-specific, cold-dependent accumulation of anthocyanins in blood oranges. Plant Cell 24(3):1242-1255.

Camm, E.L., J. McCallum, E. Leaf, and M.R. Koupai-Abyazani. 1993. Cold-induced purpling of Pinus contorta seedlings depends on previous daylength treatment. Plant Cell Environ. 16(6):761-764.

Chalker-Scott, L. 1999. Environmental significance of anthocyanins in plant stress responses. Photochem. Photobiol. 70(1):1-9.

De Beer, D., E. Joubert, W.C. Gelderblom, and M. Manley. 2003. Antioxidant activity of South African red and white cultivar wines: Free radical scavenging. J. Agr. Food Chem. 51(4):902909.

Deighton, N., R. Brennan, C. Finn, and H.V. Davies. 2000. Antioxidant properties of domesticated and wild Rubus species. J. Sci. Food Agr. 80(9):1307-1313.

Dutt, M. and J.W. Grosser. 2009. Evaluation of parameters affecting Agrobacterium-mediated transformation of citrus. Plant Cell Tiss. Org. 98(3):331-340.

Dutt, M. and J.W. Grosser. 2010. An embryogenic suspension cell culture system for Agrobacterium-mediated transformation of citrus. Plant Cell Rpt. 29(11):1251-1260.

Dutt, M., V. Orbovic, and J.W. Grosser. 2009. Cultivar dependent gene transfer into citrus using Agrobacterium. Proc. Florida State Hort. Soc. 122:85-89.

Dutt, M., M. Vasconcellos, and J. Grosser. 2011. Effects of antioxidants on Agrobacterium-mediated transformation and accelerated production of transgenic plants of mexican lime (Citrus aurantifolia Swingle). Plant Cell Tissue Organ Cult. 107(1):79-89.

Espley, R.V., R.P. Hellens, J. Putterill, D.E. Stevenson, S. Kutty-Amma, and A.C. Allan. 2007. Red colouration in apple fruit is due to the activity of the MYB transcription factor, MdMYB10. Plant J. 49(3):414-427.

Goldsbrough, A.P., Y. Tong, and J.I. Yoder. 1996. Lc as a non-destructive visual reporter and transposition excision marker gone for tomato. Plant J. 9(6):927-933.

Gonzali, S., A. Mazzucato, and P. Perata. 2009. Purple as a tomato: Towards high anthocyanin tomatoes. Trends Plant Sci. 14(5):237-241.

Goren, R., M. Huberman, and E. Goldschmidt. 2004. Girdling: Physiological and horticultural aspects. Hort. Rev. 30:1-36.

Gould, K.S., T.C. Vogelmann, T. Han, and M.J. Clearwater. 2002. Profiles of photosynthesis within red and green leaves of Quintinia serrata. Physiol. Plant. 116(1):127-133.

Griesser, M., T. Hoffmann, M.L. Bellido, C. Rosati, B. Fink, R. Kurtzer, A. Aharoni, J. Munoz-Blanco, and W. Schwab. 2008. Redirection of flavonoid biosynthesis through the down-regulation of an anthocyanidin glucosyltransferase in ripening strawberry fruit. Plant Physiol. 146(4):1528-1539.

Hillebrand, S., M. Schwarz, and P. Winterhalter. 2004. Characterization of anthocyanins and pyranoanthocyanins from blood orange [Citrus sinensis (L.) Osbeck] juice. J. Agr. Food Chem. 52(24):73317338.

Holton, T.A. and E.C. Cornish. 1995. Genetics and biochemistry of anthocyanin biosynthesis. Plant Cell 7(7):1071-1083.
Hood, E.E., S.B. Gelvin, L.S. Melchers, and A. Hoekema. 1993. New Agrobacterium helper plasmids for gene transfer to plants. Transgenic Res. 2:208-218.

Irani, N.G., J.M. Hernandez, and E. Grotewold. 2003. Chapter three regulation of anthocyanin pigmentation. Recent Adv. Phytochem. 37:59-78.

Jaakola, L. 2013. New insights into the regulation of anthocyanin biosynthesis in fruits. Trends Plant Sci. 18(9):477-483.

Jeong, S.T., N. Goto-Yamamoto, K. Hashizume, S. Kobayashi, and M. Esaka. 2006. Expression of VvmybAl gene and anthocyanin accumulation in various grape organs. Amer. J. Enol. Viticult. 57(4):507-510.

Karageorgou, P. and Y. Manetas. 2006. The importance of being red when young: Anthocyanins and the protection of young leaves of Quercus coccifera from insect herbivory and excess light. Tree Physiol. 26(5):613-621.

Lee, H.S. 2002. Characterization of major anthocyanins and the color of red-fleshed budd blood orange (Citrus sinensis). J. Agr. Food Chem. 50(5):1243-1246.

Li, C.Y., D. Weiss, and E.E. Goldschmidt. 2003. Girdling affects carbohydrate-related gene expression in leaves, bark and roots of alternate-bearing citrus trees. Ann. Bot. (Lond.) 92(1):137-143.

Li, H., H. Flachowsky, T.C. Fischer, M.V. Hanke, G. Forkmann, D. Treutter, W. Schwab, T. Hoffmann, and I. Szankowski. 2007. Maize Lc transcription factor enhances biosynthesis of anthocyanins, distinct proanthocyanidins and phenylpropanoids in apple (Malus domestica Borkh.). Planta 226(5):1243-1254.

Liang, Z., B. Wu, P. Fan, C. Yang, W. Duan, X. Zheng, C. Liu, and S. Li. 2008. Anthocyanin composition and content in grape berry skin in Vitis germplasm. Food Chem. 111(4):837-844.

Lila, M.A. 2004. Anthocyanins and human health: An in vitro investigative approach. J. Biomed. Biotechnol. 2004(5):306-313.

Lin-Wang, K., D. Micheletti, J. Palmer, R. Volz, L. Lozano, R. Espley, R.P. Hellens, D. Chagne, D.D. Rowan, and M. Troggio. 2011. High temperature reduces apple fruit colour via modulation of the anthocyanin regulatory complex. Plant Cell Environ. 34(7):1176-1190.

Livak, K.J. and T.D. Schmittgen. 2001. Analysis of relative gene expression data using real-time quantitative PCR and the $2^{-\Delta \Delta \mathrm{Ct}}$ method. Methods 25(4):402-408.

Manach, C., A. Scalbert, C. Morand, C. Rémésy, and L. Jiménez. 2004. Polyphenols: Food sources and bioavailability. Amer. J. Clin. Nutr. 79(5):727-747.

Markham, K.R., K.S. Gould, C.S. Winefield, K.A. Mitchell, S.J. Bloor, and M.R. Boase. 2000. Anthocyanic vacuolar inclusions-their nature and significance in flower colouration. Phytochemistry 55(4):327-336.

Meng, X., B. Yin, H.L. Feng, S. Zhang, X.Q. Liang, and Q.W. Meng. 2014. Overexpression of R2R3-MYB gene leads to accumulation of anthocyanin and enhanced resistance to chilling and oxidative stress. Biol. Plant. 58(1):121-130.

Mori, K., N. Goto-Yamamoto, M. Kitayama, and K. Hashizume. 2007. Loss of anthocyanins in red-wine grape under high temperature. J. Expt. Bot. 58(8):1935-1945.

Murray, J.R. and W.P. Hackett. 1991. Dihydroflavonol reductase activity in relation to differential anthocyanin accumulation in juvenile and mature phase Hedera helix L. Plant Physiol. 97(1):343-351.

Naz, S., R. Siddiqi, S. Ahmad, S. Rasool, and S. Sayeed. 2007. Antibacterial activity directed isolation of compounds from Punica granatum. J. Food Sci. 72(9):M341-M345.

Neill, S.O. and K.S. Gould. 2003. Anthocyanins in leaves: Light attenuators or antioxidants? Funct. Plant Biol. 30(8):865-873.

Peach, C. and J. Velten. 1991. Transgene expression variability (position effect) of CAT and GUS reporter genes driven by linked divergent T-DNA promoters. Plant Mol. Biol. 17(1):49-60.

Pourcel, L., N.G. Irani, Y. Lu, K. Riedl, S. Schwartz, and E. Grotewold. 2010. The formation of anthocyanic vacuolar inclusions in Arabidopsis thaliana and implications for the sequestration of anthocyanin pigments. Mol. Plant 3(1):78-90. 
Poustka, F., N.G. Irani, A. Feller, Y. Lu, L. Pourcel, K. Frame, and E. Grotewold. 2007. A trafficking pathway for anthocyanins overlaps with the endoplasmic reticulum-to-vacuole protein-sorting route in Arabidopsis and contributes to the formation of vacuolar inclusions. Plant Physiol. 145(4):1323-1335.

Qiu, J., S. Sun, S. Luo, J. Zhang, X. Xiao, L. Zhang, F. Wang, and S. Liu. 2014. Arabidopsis AtPAP1 transcription factor induces anthocyanin production in transgenic Taraxacum brevicorniculatum. Plant Cell Rpt. 33(4):669-680.

Reyes, L.F., J.C. Miller, Jr., and L. Cisneros-Zevallos. 2004. Environmental conditions influence the content and yield of anthocyanins and total phenolics in purple- and red-flesh potatoes during tuber development. Amer. J. Potato Res. 81(3):187-193.

Saija, A. 1994. Pharmacological effects of anthocyanins from blood orange juice. Essenze Deriv. Agrum. 64(2):229-233.

Sánchez-Moreno, C. 2002. Review: Methods used to evaluate the free radical scavenging activity in foods and biological systems. Food Sci. Technol. Intl. 8(3):121-137.

Steyn, W.J., S.J.E. Wand, D.M. Holcroft, and G. Jacobs. 2002. Anthocyanins in vegetative tissues: A proposed unified function in photoprotection. New Phytol. 155(3):349-361.

Stiles, E.A., N.B. Cech, S.M. Dee, and E.P. Lacey. 2007. Temperaturesensitive anthocyanin production in flowers of Plantago lanceolata. Physiol. Plant. 129(4):756-765.

Stover, E., Y. Avila, Z.T. Li, and D. Gray. 2013. Transgenic expression in citrus of Vitis MybA1 from a bidirectional promoter resulted in variable anthocyanin expression and was not suitable as a screenable marker without antibiotic selection. Proc. Florida State Hort. Soc. 126:84-88.

Takos, A.M., F.W. Jaffé, S.R. Jacob, J. Bogs, S.P. Robinson, and A.R. Walker. 2006. Light-induced expression of a MYB gene regulates anthocyanin biosynthesis in red apples. Plant Physiol. 142(3):12161232.

Tsuda, T., F. Horio, K. Uchida, H. Aoki, and T. Osawa. 2003. Dietary cyanidin 3-O-beta-D-glucoside-rich purple corn color prevents obesity and ameliorates hyperglycemia in mice. J. Nutr. 133(7):2125-2130.

Tsuda, T., K. Shiga, K. Ohshima, S. Kawakishi, and T. Osawa. 1996. Inhibition of lipid peroxidation and the active oxygen radical scavenging effect of anthocyanin pigments isolated from Phaseolus vulgaris. J. Biochem. Pharmacol. 52(7):1033-1039.

Vlachonasios, K.E., M.F. Thomashow, and S.J. Triezenberg. 2003. Disruption mutations of ADA2b and GCN5 transcriptional adaptor genes dramatically affect Arabidopsis growth, development, and gene expression. Plant Cell 15(3):626-638.

Wang, H., G. Cao, and R.L. Prior. 1997. Oxygen radical absorbing capacity of anthocyanins. J. Agr. Food Chem. 45(2):304-309.

Xiaonan, Y. and Z. Qixiang. 2002. Anthocyanin in ornamental plant and color express. Scientia Silvae Sincae 38(3):147-153.

Zhang, H., L. Wang, S. Deroles, R. Bennett, and K. Davies. 2006. New insight into the structures and formation of anthocyanic vacuolar inclusions in flower petals. BMC Plant Biol. 6:29.

Zheng, H., O. Rowland, and L. Kunst. 2005. Disruptions of the Arabidopsis enoyl-CoA reductase gene reveal an essential role for very-long-chain fatty acid synthesis in cell expansion during plant morphogenesis. Plant Cell 17(5):1467-1481. 